\title{
Archéopages Archéopages
}

Archéologie et société

Hors-série 3 | 2012

Nouveaux champs de la recherche archéologique

\section{Projets d'activités scientifiques et axes de recherche 2006-2009: une politique scientifique de l'Inrap}

Anne Augereau

\section{CpenEdition}

\section{Journals}

Édition électronique

URL : https://journals.openedition.org/archeopages/463

DOI : 10.4000/archeopages.463

ISSN : 2269-9872

Éditeur

INRAP - Institut national de recherches archéologiques préventives

Édition imprimée

Date de publication : 1 janvier 2012

Pagination : 48-50

ISSN : 1622-8545

\section{Référence électronique}

Anne Augereau, «Projets d'activités scientifiques et axes de recherche 2006-2009: une politique scientifique de l'Inrap », Archéopages [En ligne], Hors-série 3 | 2012, mis en ligne le 01 janvier 2012, consulté le 11 mars 2023. URL : http://journals.openedition.org/archeopages/463 ; DOI : https:// doi.org/10.4000/archeopages.463 


\begin{tabular}{|c|c|c|c|c|c|}
\hline Intitulé de l'axe & $\begin{array}{l}\text { Études } \\
\text { collectives }\end{array}$ & $\begin{array}{l}\text { Articles, } \\
\text { monographies }\end{array}$ & $\begin{array}{l}\text { Nombre total } \\
\text { de projets }\end{array}$ & $\begin{array}{c}\text { Équivalence } \\
\text { en nombre } \\
\text { de jours-homme }\end{array}$ & \% Jours-homme \\
\hline $\begin{array}{l}\text { Le Paléolithique inférieur et moyen : } \\
\text { synthèse des données issues } \\
\text { de fouilles récentes et comparaisons } \\
\text { sud-ouest/nord-ouest }\end{array}$ & 5 & 1 & 6 & 2099 & 8,3 \\
\hline $\begin{array}{l}\text { Approches territoriales du Néolithique } \\
\text { ancien et moyen : chronologie, dyna- } \\
\text { miques d'implantations et nature des sites. }\end{array}$ & 12 & 4 & 16 & 2586 & 10,2 \\
\hline $\begin{array}{l}\text { L'occupation du sol à l'âge du Bronze } \\
\text { et au début du premier âge du Fer }\end{array}$ & 3 & 1 & 4 & 1059 & 4,2 \\
\hline $\begin{array}{l}\text { Organisation des territoires ruraux à la } \\
\text { fin du premier et au second âge du Fer. }\end{array}$ & 5 & 10 & 15 & 1642 & 6,5 \\
\hline L'espace urbain et ses composantes & 14 & 10 & 24 & 4996 & 19,7 \\
\hline $\begin{array}{l}\text { Données récentes sur le peuplement } \\
\text { précolombien et amérindien en Amé- } \\
\text { rique du Sud et dans les Caraïbes }\end{array}$ & 3 & 1 & 4 & 145 & 0,6 \\
\hline $\begin{array}{l}\text { La fin du Néolithique aux pourtours } \\
\text { du bassin parisien }\end{array}$ & 3 & 0 & 3 & 723 & 2,9 \\
\hline $\begin{array}{c}\text { Architectures, pratiques funéraires } \\
\text { et paléoanthropologie au Bronze } \\
\text { moyen et final }\end{array}$ & 1 & 2 & 3 & 487 & 1,9 \\
\hline $\begin{array}{l}\text { Pratiques funéraires et sociétés : } \\
\text { diversité des modes de sépultures } \\
\text { au cours de l'âge du Fer }\end{array}$ & 3 & 9 & 12 & 1273 & 5,0 \\
\hline $\begin{array}{l}\text { Le plateau des Guyanes et les Petites } \\
\text { Antilles : processus de peuplement } \\
\text { et diffusions de la culture matérielle }\end{array}$ & 1 & 0 & 1 & 56 & 0,2 \\
\hline $\begin{array}{l}\text { L'évolution des terroirs au travers } \\
\text { des opérations de grande ampleur }\end{array}$ & 6 & 3 & 9 & 1712 & 6,8 \\
\hline $\begin{array}{l}\text { Développement de référentiels } \\
\text { chrono-typologiques des mobiliers, } \\
\text { pour les périodes allant de l'âge } \\
\text { du Bronze à la période moderne }\end{array}$ & 18 & 9 & 27 & 3565 & 14,1 \\
\hline TOTAL & 95 & 78 & 173 & 25303 & \\
\hline
\end{tabular}

[Fig. 1] Les axes de recherche 2006-2009: publications sorties et jours-hommes investis. 


\section{Projets d'activités scientifiques et axes de recherche 2006-2009: une politique scientifique de l'Inrap}

Anne Augereau

Inrap

M ission confiée par le législateur, la recherche est au cœur des activités de l'Inrap et en constitue la finalité. C'est dans ce domaine que cette institution s'impose dans le paysage archéologique national. Production cumulative, discipline d'érudition, l'archéologie préventive doit être plus que la somme des données récoltées quotidiennement lors des opérations de terrain : avancées méthodologiques et apports cognitifs doivent être mis en valeur et pleinement exploités. Dans ce cadre, diagnostics et fouilles sont au centre de la démarche scientifique, de la politique de recherche de l'Inrap puisqu'ils alimentent les grands questionnements archéologiques.

Mais il convient d'en évaluer précisément l'apport en faisant le bilan de l'activité passée, en établissant une programmation scientifique prospective, en mettant en œuvre une politique d'exploitation et de publication des données, et en développant les partenariats et les collaborations. C'est pourquoi, depuis 2003, les PAIR (Projet d'activité individuelle de recherche) et, depuis 2005, les PAS (Projets d'activités scientifiques) permettent aux agents de l'Inrap, souvent en collaboration avec les représentants de diverses institutions, de mettre en œuvre des activités de recherche et de publication. Depuis 2006, afin de donner une cohérence à cette démarche et la fonder sur la réalité du terrain, une programmation scientifique a été établie avec l'aide du conseil scientifique de l'Inrap ; elle donne un cadre à ces actions.

\section{La programmation et les axes de recherche} 2006-2009. La programmation scientifique propre à l'établissement a été validée en 2006 par le conseil scientifique. Elle complète les thématiques déjà abordées dans le cadre des ACR (Actions collectives de recherches), PCR (Programmes collectifs de recherches) et APP (Aides à la préparation de publication) autorisés par le ministère de la culture et de la communication. Les thèmes développés peuvent s'articuler avec les programmes déployés au sein des UMR et sont évidemment ouverts à l'ensemble des acteurs de la recherche archéologique (CNRS, enseignement supérieur, ministère de la culture, services archéologiques de collectivité). Cette programmation peut prendre deux formes principales, selon l'échelle d'analyse.

D'une part, les enquêtes nationales correspondent à des commandes de la direction scientifique et technique et couvrent l'ensemble du territoire national. Elles sont destinées à établir les avancées de la recherche dans certains domaines d'étude selon des choix et une méthodologie définie collectivement. Deux enquêtes nationales sont encore actuellement en cours : « L'organisation et lévolution du territoire rural au second âge du fer » (responsables : Gertrude Blancquaert, François Malrain) [cf. article p 147] ; « L'occupation du sol à lâge du Bronze et au début du premier âge du fer » (responsables : Laurent Carozza, Cyril Marcigny et Marc Talon) [cf. article p133].

D'autre part, des projets concernent des territoires ou des thématiques plus restreints. Ils peuvent donner lieu à des publications de synthèses, à des ouvrages monographiques, à des collectifs de recherche avec objectif de publication. À terme, un grand nombre de domaines d'études devrait donc être couvert par les projets de ce type. Dix-sept axes de recherche ont été développés de 2006 à 2009 [Fig.1]. Ces enquêtes et ces axes ont été présentés au CNRA afin que celui-ci puisse les intégrer à une réflexion plus générale sur la programmation scientifique et ainsi assurer la cohérence de la recherche archéologique nationale. Bien entendu, l'Inrap est attentif aux souhaits que cette instance pourrait émettre.

Le bilan. Fin 2010, 173 projets avaient été mis en chantier dans le cadre de ces axes. Ils ont donné sujet à de nombreuses publications [Fig. 2]. En moyenne, chaque projet a donné ou donnera 2,4 publications. Par rapport aux moyens octroyés, cela équivaut en moyenne à 2 ou 3 publications pour un équivalent temps plein investi; 2 publications si on ne considère que les publications sorties, 3 , si on fait le calcul en additionnant publications, sorties et manuscrits rendus en attente. Ce bon résultat global est cependant très contrasté d'une période chronologique à l'autre. Ainsi, en comparant le nombre de jours-homme investis dans les opérations de fouilles, représentatifs de l'activité de terrain sur une période archéologique donnée, avec le nombre de jours PAS par période, on constate que les données sur l'Antiquité, période très représentée en fouille, restent encore trop peu analysées [Fig. 3]. Il en est de même, dans une moindre mesure, pour le Moyen Âge et en particulier pour le Haut Moyen Âge rural. Cette masse documentaire, qui a fourni des informations considérables, notamment sur les campagnes, peine à être exploitée. De plus, la communauté scientifique ne semble pas avoir pris totalement la mesure des apports de l'archéologie préventive dans ces périodes et les programmes de recherche ne se sont sans doute pas assez développés. Ce manque de programmes sur l'Antiquité s'est ainsi répercuté sur les projets déposés par les équipes de l'institut. Enfin, la ventilation des axes en grand découpage chronologique dessert en partie la période antique, comme la période médiévale, dans la mesure où de nombreux projets de cette période se trouvent dans l'axe sur les référentiels chrono-culturels ou encore dans celui sur l'évolution des terroirs. Enfin, la faiblesse de la production éditoriale pour l'Antiquité sera sans doute un peu pondérée par l'analyse des publications réalisées dans le cadre des budgets déconcentrés. Mais ce dernier point ne compensera cependant pas une production insuffisante qu'il conviendra de veiller à augmenter dans le prochain quadriennal, au risque d'une déconnexion croissante entre données de terrain et recherche. 


\begin{tabular}{|c|c|c|}
\hline Intitulé Axe & $\begin{array}{c}\text { Nombre de publications } \\
\text { sorties ou sous presse }\end{array}$ & $\begin{array}{c}\text { Nombre de publications } \\
\text { à paraître }\end{array}$ \\
\hline Paléo. inf. et moyen & 45 & 22 \\
\hline Approches territ. Néo. anc. et moy. & 17 & 1 \\
\hline Occupation sols Bronze $/ 1^{\text {er }}$ Fer & $\mathrm{o}$ & $\mathrm{o}$ \\
\hline Territ ruraux âges du Fer & 25 & $\mathrm{O}$ \\
\hline Campagnes durant l'Antiquité & 1 & 4 \\
\hline Haut Moyen Âge rural & 11 & 5 \\
\hline Espace urbain & 16 & 1 \\
\hline Précolombien, Amérindien & o & o \\
\hline Fin Néo. bassin parisien & 12 & 23 \\
\hline Pratiques funéraires âge du Bronze & o & 1 \\
\hline Pratiques funéraires âges du Fer & 20 & 6 \\
\hline Pratiques funéraires Antiquité & 4 & 1 \\
\hline Archéo. religieuse et funéraire urbaine & 6 & o \\
\hline Production et travail du fer & 1 & 3 \\
\hline Peuplements Guyane et Petites Antilles & 4 & 3 \\
\hline Evolution des terroirs & 68 & 34 \\
\hline Référentiels typo-chronologiques & 42 & 61 \\
\hline TOTAL & 272 & 165 \\
\hline & \multicolumn{2}{|c|}{$\mathbf{4 3 7}$} \\
\hline
\end{tabular}

\begin{tabular}{|c|c|c|c|c|}
\hline Période & $\begin{array}{l}\text { Fouilles 2006-2009 } \\
\qquad(\% \mathrm{j} / \mathrm{h})\end{array}$ & $\begin{array}{c}\text { PAS 2006-2009 } \\
(\% \mathrm{j} / \mathrm{h})\end{array}$ & $\begin{array}{c}\text { Nombre de } \\
\text { publications sorties }\end{array}$ & $\begin{array}{c}\text { Taux de publications } \\
\text { sorties (\%) }\end{array}$ \\
\hline Paléolithique & 3 & 8,3 & 67 & 15,3 \\
\hline Néolithique & 13 & 13,1 & 53 & 12,1 \\
\hline Proto-Histoire & 25 & 20,2 & 56 & 12,8 \\
\hline Antiquité & 34 & 9,2 & 10 & 2,3 \\
\hline Moyen Âge & 21 & 7,8 & 22 & 5,0 \\
\hline $\begin{array}{l}\text { Moderne ou transition } \\
\text { chronologique \& DOM }\end{array}$ & 4 & 41,4 & 229 & 52,4 \\
\hline TOTAL & 100 & 100 & 437 & 100 \\
\hline
\end{tabular}

[Fig.2] Nombre global de publications en lien avec les axes de recherche 2006-2009
[Fig.3] Nombre de publications sorties par période chronologique 